\title{
Effect of heptane food simulating liquid on surface microhardness of 4 composites (Filtek Z250, Aelite, Filtek Z350 and Clearfil ST)
}

\author{
Niusha Golbari ${ }^{1}$, Morad Sadaghianii ${ }^{2 *}$, Anahit Afrasiabi ${ }^{3}$, Mahdi Allahdadi $^{4}$, Elmira Najafrad ${ }^{5}$ \\ and Ehsan Sadeghi Ziaratgahi ${ }^{6}$ \\ ${ }^{1}$ DDS. Post Graduate Student of Restorative Dentistry Department, Dental School, Shahid Beheshti University \\ of Medical Sciences, Tehran, Iran \\ ${ }^{2}$ Department of Restorative Dentistry, Islamic Azad University, Dental Branch, Tehran, Iran \\ ${ }^{3}$ DDS. Post Graduate Student of Restorative Dentistry Department, Dental School, Shahid Beheshti University \\ of Medical Sciences, Tehran, Iran \\ ${ }^{4}$ DDS. Post Graduate Student of Restorative Dentistry Department, Dental School, Shahid Beheshti University \\ of Medical Sciences, Tehran, Iran \\ ${ }^{5}$ DDS. Post Graduate Student of Restorative Dentistry Department, Dental School, Hamadan University of \\ Medical Sciences, Tehran, Iran \\ ${ }^{6}$ DDS. Post Graduate Student of Restorative Dentistry Department, Dental School, Shahid Beheshti University \\ of Medical Sciences, Tehran, Iran
}

\section{ABSTRACT}

Resin based composites are became more and more popular in restorative dentistry, particularly because of their esthetic aspects. Decreasing the microhardness of dental restorative composites after curing in oral environment can influence their clinical durability. The aim of the current study was to determine effect of food simulating liquids 50\% heptane on surface microhardness of Z250 microhybrid, Aelite nanofilled Z350 and Clearfil nanohybrid composites. 20 specimens of each composite were prepared in a prefabricated mold with 5 diameter and $2 \mathrm{~mm}$ depth. All the specimens composite were stored in distilled water, immediately after curing for 24 hours as the control group. Then the specimens were taken out of the solution and washed, dried and then surface microhardness of specimens was evaluated by the microhardness device based on Vickers. These specimens were divided into two groups randomly;

\section{ARTICLE INFORMATION:}

*Corresponding Author: Morad_Sadaghiani@yahoo.com Received 23rd July, 2017

Accepted after revision $28^{\text {th }}$ Sep, 2017

BBRC Print ISSN: 0974-6455

Online ISSN: 2321-4007 CODEN: USA BBRCBA

Thomson Reuters ISI ESC and Crossref Indexed Journal

NAAS Journal Score 2017: 4.31 Cosmos IF: 4.006

$\odot$ A Society of Science and Nature Publication, 2017. All rights reserved.

Online Contents Available at: http//www.bbrc.in/

DOI: $10.21786 / \mathrm{bbrc} / 10.3 / 3$ 
each of them was immersed in one of the following solutions distilled water, 50\% heptane for 7 days at $37{ }^{\circ} \mathrm{C}$. After one week conditioning period microhardness testing was carried out. The data were analyzed by 2 way ANOVA and Tucky HSD test. According to the results, there were significant differences on the initial microhardness of all composites in water $(\mathrm{p}<0.05)$. Microhardness of the Z250 was higher than the other groups in water and heptane $(p<0.05)$. A significant decrease observed on the secondary microhardness of the Aelite and Clearfil composites in heptane compared to the first time $(\mathrm{p}<0.05)$. The Clearfil had higher decrease on microhardness in water and heptane compared to the other composites $(p<0.05)$. The microhardness of composite resin materials used in this study influenced after immersion in Heptane food simulation solution and distilled water. The effect of heptane on change in surface microhardness is material dependent.

KEY WORDS: COMPOSITE,NANOHYBRID, MICROHYBRID,NANOFILL, HEPTANE, FOOD SIMULATING

\section{INTRODUCTION}

The administration of resin-based restorative materials in dentistry has increased recently because of their good aesthetic appearance, improvements in formulations, ease of handling, and ability to establish a bond to dental hard tissues. The mechanical property of the dental composites depends on the filler particles and particle size. Recent advancements on the organic matrix and inorganic fillers have led to the development of new materials with reduced particle size and increased filler loading which improved mechanical properties and aesthetics on the current composite resin materials. Restorative materials are required to have long-term continuousness while the oral cavity is a complex aqueous environment and restorative material contacts with saliva, (Catelan et al. 2010, Hengtrakool et al. 2011, Erdemir et al. 2013 George and Kavyashree 2017).

Also, low $\mathrm{pH}$ due to acidic foods and drinks may influence the mechanical and physical characteristics of the materials (Miranda et al. 2011). Physical characteristics of restorative materials are an important concern when determining suitable restorative materials because they strongly influence the clinical longevity of restorations (Seifert et al. 2011). In clinical environment, microhardness of materials decrease might contribute to its deterioration. Under in vivo conditions, composite resin materials may be exposed either discontinuously or continually to chemical agents found in saliva, food and beverages (Topcu et al. 2010). In the short- or long-term, these conditions have adverse effect on its physical and chemical structure (Valinoti et al. 2008). The material's microhardness is one of the most important properties, which correlates with resistance to intra-oral softening, compressive strength and degree of conversion (Voltarelli et al. 2010). A low surface microhardness value is largely related to inadequate wear resistance and proclivity to scratching, which can compromise fatigue strength and lead to failure of the restoration (Erdemir et al. 2013). So, the aim of the current study was to determine effect of food simulating liquids 50\% heptane on surface microhardness of Z250 microhybrid, Aelite nanofilled Z350 and Clearfil nanohybrid composites

\section{MATERIAL AND METHODS}

In this experimental in vitro study 4 composite types were used $(n=10)$. The composites allocated in stainless steel ( $5 \mathrm{~mm}$ diamater $\times 2 \mathrm{~mm}$ thickness). A smooth plate put on the composite and the produced collected at $40 \mathrm{~s}$ by SDS Kerr $\left(1000 \mathrm{~mW} / \mathrm{cm}^{2}\right)$ and polymerized $(2 \times 2)$ and polished using aluminum oxide (3M ESPE) by spraying the water. Then samples stored in distilled water $37^{\circ} \mathrm{C}$ for $24 \mathrm{~h}$. Then microhardness of the samples determined using Intender (6100 Vickers, USA).

\section{COMPOSITES}

The information of the composites used in the study was Filtek z250 Micro hybrid (filler weight 82\%, filler volume $60 \%)$ Zirconia silica $(0.6 \mu \mathrm{m})$ Bis-EMA, UDMA Bis-GMA. The Filtek Z350 was Nanofilled (filler weight 78.5\%, filler volume 59.5\%) Zro2/sio2 nanocluster, Sio2 nanofiller (5-20nm) Bis-GMA Bis-EMA UDMA TEGDMA. The Aelite was Nanofilled (filler weight 73\%, filler volume 54\%) Glass frit Amouphous silica (0.04-5um) Exhoxylated Bisphenol A Dimethacrylate TEGDMA. The ClearfilMajesty ES-2 was Nanohybrid (filler weight 93\%, filler volume 81\%) Silanatedbarium glass filler Pre-polymerized organic filler $(0.04-1 \mu \mathrm{m})$ hydrophobic aromatic dimethacyilate TEG-DMA Bis-GMA. The $50 \mathrm{gr}$ force for $15 \mathrm{~s}$ is done using Intender on 3 points in each sample. Then the microhardness of the samples determined. The 10 samples allocated into the heptane and 10 in distilled water for 7 days. After one week conditioning period microhardness testing was carried out.

\section{STATISTICAL ANALYSIS}

The data were analyzed by 2way ANOVA and Tucky HSD test using SPSS 16.0 for Windows (SPSS, Inc., Chicago, IL, USA). $\mathrm{P}<0.05$ was considered as significant differences between treatments. 


\section{RESULTS AND DISCUSSION}

According to the results, there were significant differences on the initial microhardness of all composites in water ( $p<0.05)$. Microhardness of the Z250 was higher than the other groups in water and heptane $(\mathrm{p}<0.05)$. No significant difference observed on primary microhardness of Aelite and Clearfi l ( $p>0.05)$. A significant decrease observed on the secondary microhardness of the Aelite and Clearfi l composites in heptane compared to the first time $(p<0.05)$. The microhardness of Clearfi 1 significantly decreased compard to the other composites in water and heptane conditions.

As seen in table 2, a significant differences observed between primary and secondary microhardness of the $\mathrm{Z} 350(65.30 \pm 6.19$ and $75.84 \pm 4.25), 75.84 \pm 4.25$

\begin{tabular}{|c|c|c|c|}
\hline Composite & \begin{tabular}{|l|} 
Food \\
suspension
\end{tabular} & $\begin{array}{c}\text { Primary } \\
\text { microhardness }\end{array}$ & $\begin{array}{c}\text { Secondary } \\
\text { microhardness }\end{array}$ \\
\hline \multirow[t]{2}{*}{ Z350 } & $\begin{array}{l}\text { distilled } \\
\text { water }\end{array}$ & 65.3000 & 75.8450 \\
\hline & Heptane & 63.8390 & 67.3380 \\
\hline \multirow[t]{2}{*}{ Aelite } & $\begin{array}{l}\text { distilled } \\
\text { water }\end{array}$ & 73.6970 & 85.2210 \\
\hline & Heptane & 77.3370 & 82.7360 \\
\hline \multirow[t]{2}{*}{ Z250 } & $\begin{array}{l}\text { distilled } \\
\text { water }\end{array}$ & 50.8810 & 39.8760 \\
\hline & Heptane & 50.8720 & 39.8550 \\
\hline \multirow[t]{2}{*}{ Clearfil } & $\begin{array}{l}\text { distilled } \\
\text { water }\end{array}$ & 43.6690 & 35.4780 \\
\hline & Heptane & 43.4300 & 33.5460 \\
\hline
\end{tabular}

Table 2. the primary and secondary microhardness of composite stored in distilled water

\begin{tabular}{|l|c|c|c|}
\hline Composite & $\begin{array}{c}\text { Primary } \\
\text { distilled water }\end{array}$ & $\begin{array}{c}\text { Secondary } \\
\text { distilled water }\end{array}$ & P value \\
\hline Z350 & $65.30 \pm 6.19$ & $75.84 \pm 4.25$ & 0.0001 \\
\hline $75.84 \pm 4.25$ & $50.88 \pm 7.47$ & $39.87 \pm 5.07$ & 0.015 \\
\hline Z250 & $73.69 \pm 3.69$ & $85.22 \pm 9.33$ & 0.0001 \\
\hline Clearfil & $43.66 \pm 4.99$ & $35.47 \pm 4.61$ & 0.013 \\
\hline
\end{tabular}

Table 3. the primary and secondary microhardness of composite stored in heptane

\begin{tabular}{|l|c|c|c|}
\hline Composite & $\begin{array}{c}\text { Primary } \\
\text { heptane }\end{array}$ & $\begin{array}{c}\text { Secondary } \\
\text { heptane }\end{array}$ & P value \\
\hline Z350 & $63.83 \pm 3.55$ & $67.33 \pm 5.95$ & 0.226 \\
\hline Aelite & $50.87 \pm 6.41$ & $39.85 \pm 6.90$ & 0.006 \\
\hline Z250 & $77.33 \pm 6.27$ & $82.73 \pm 3.68$ & 0.064 \\
\hline Clearfil & $43.43 \pm 4.46$ & $33.54 \pm 2.62$ & 0.0001 \\
\hline
\end{tabular}

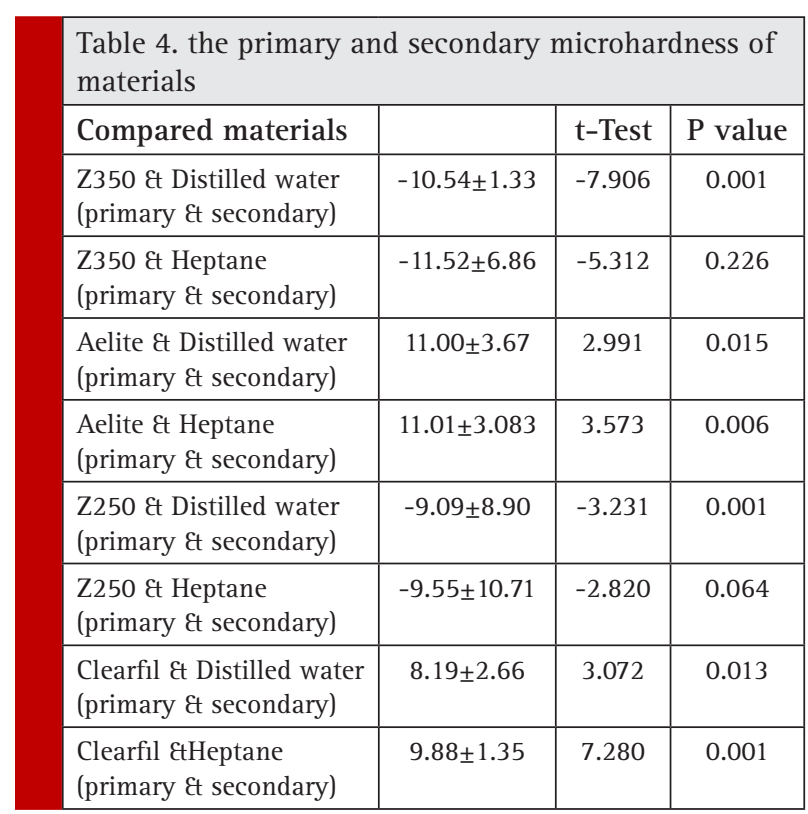

$(50.88 \pm 7.47$ and $39.87 \pm 5.07), \quad Z 250(73.69 \pm 3.69$ and $85.22 \pm 9.33)$ and Clearfil $(43.66 \pm 4.99$ and $35.47 \pm 4.61)$.

As seen in table 3, significant difference was observed on microhardness of Aelite (0.006) and Clearfil (0.0001) stored in heptane.

The primary and secondary microhardness of materials is presented in table 4 .

\section{DISCUSSION}

During consumption of food or drink contacts teeth or restoration surfaces for only a short time before it is washed away by saliva. Usually contact of teeth with acidic food or drink for a prolonged period of time and the situation did not account for the role of saliva (Erdemir et al. 2013). As observed in the current study, surface microhardness of Z250 was higher than the other groups. After 24 hours distilled water had significant effect on all the specimens. After 7days distilled water had significant effect on all groups however, Heptane had significant effect on Aelite and Clearfil specimens. According to analyses after both 24 hours and 7 days Z250 and Z30 specimens showed increase in microhardness while Aelite and Clearfil showed significant decrease in microhardness. Clearfil presented the lowest microhardness values. Distilled water was selected instead of artificial saliva to simulate the aching effect of saliva because the artificial saliva storage medium is not considered to be a more clinically relevant environment (Erdemir et al. 2013).

The surface microhardness index of all restorative materials after a week of storage in distilled water was higher than the baseline surface microhardness val- 
ues. This could possibly be explained by the amplified monomer conversion and additional post-curing cross-linking reactions in the resin phase over the time. Compoglass F, Filtek Z250, Filtek Supreme and Premise specimens stored in distilled water had lower surface microhardness reductions compared to the specimens immersed in sports and energy drinks (Erdemir et al. 2013). In a study using Meliodent, FuturaGen and hard GC reline.

Rajaee et al. (2014) reported heptane conditioning decreased the flexural strength of Meliodent and FuturaGen and microhardness of FuturaGen. Ethanol solution had the most adverse effect on the microhardness and flexural strength of the tested resin materials (Rajaee et al. 2014). Takahashi et al. (1998) reported that water immersion had different effects on the flexural strength and microhardness of different denture base and reline resin materials. They concluded that the results could be due to the fact that the intrinsic strength of the resin and the amount of water sorption in the system influences the mechanical strength of water absorbed acrylic resins. It is reported two days of immersion in the water lead to a reduction in the microhardness of the resin samples. As mentioned, water absorption and continuation of the acrylic polymerization process is time-dependent and diffusion-controlled Azevedo et al. (2005). Organic solutions may damage the resin matrix (heptane and aqueous ethanol solution). On the other hand, water and citric acids can damage organic fillers. Therefore organic solutions could decrease flexural strength and microhardness of dental resins (Yesilyurt et al. 2009).

In a study, Yanikoğlu et al. (2009) determined the surface microhardness of filled (Estelite), nanofil (Ælite), unfilled (Valux Plus), hybrid (Tetric ceram) and Ormocerbased (Admira) composite resins in tea, coffee, Turkish coffee, mouthwash, cola, and distilled water. Based on their report the microhardness values of composite materials were statistically different in different immersion solutions. The acidity may change the polymeric matrixes of composite resin affecting dimethacrylate monomer present in their compositions (Al-Samadani, 2013). A previous study suggested that, by lowering the solutions' $\mathrm{pH}$, there is production of methacrylic acid that results in the sorption and hygroscopic expansion as a consequence of enzymatic hydrolysis and biodegradation (Sripetchdanond and Leevailoj, 2014). It was observed that sodium fluoride containing mouth rinses also reduce the surface microhardness (Sripetchdanond and Leevailoj, 2014).

In a recent study, George et al (2017) on effect of four mouth rinses on microhardness of resin composite (Filtek ${ }^{\mathrm{TM}}$ P60) material (3M ESPE St. Paul, MN, USA) reported all the mouth rinses showed reduction in surface microhardness of the esthetic restorative material. Yesilyurt et al. (2009) reported microhardness of silorane-based composite was not influenced by ethanol significantly, which could be due to the hydrophobicity of the resin matrix. Except for Bis-EMA, all other molecules (Bis-GMA, UDMA, and TEGDMA) have hydroxyl groups, which promote water sorption. As for silorane-based composite, it has 3,4-epoxycyclohexyl-cyclopolymethylsiloxane. In conclusion, the microhardness of composite resin materials used in this study influenced by food simulation solutions. The effect of heptane on change in surface microhardness is material dependent.

\section{REFERENCES}

Al-Samadani KH. 2013 Color stability of restorative materials in response to Arabic coffee, Turkish coffee and Nescafe. J Contemp Dent Pract. 14:681-90.

Azevedo A, Machado AL, Vergani CE, Giampaolo ET,Pavarina AC. 2005 Hardness of denture base and hard chair-side reline acrylic resins. J Applied Oral Sci. 13: 291-295.

Catelan KA, Briso AL, Sundfeld RH, Santos PH. 2010 Effect of artifcial aging on the roughness and microhardness of sealed composites. J Esthet Restor Dent. 22:324-30.

Erdemir U, Yildiz E, Eren MM, Ozel S.2013 Surface hardness evaluation of different composite resin materials: influence of sports and energy drinks immersion after a short-term period. J Appl Oral Sci. 21(2):124-31.

George R. and Kavyashree G. 2017 Effect of four mouth rinses on microhardness of esthetic restorative material: An in vitro study. J Int Oral Health 2017;9:55-9.

Hengtrakool C, Kukiattrakoon B, Kedjarune-Leggat U. 2011 Effect of naturally acidic agents on microhardness and surface micromorphology of restorative materials. Eur J Dent. 5:89100.

Miranda DA, Bertoldo CE, Aguiar FH, Lima DA, Lovadino JR. 2011 Effects of mouthwashes on Knoop hardness and surface roughness of dental composites after different immersion times. Braz Oral Res. 25:168-73.

Rajaee N, Vojdani M, Adibi S. 2014 Effect of food simulating agents on the flexural strength and surface hardness of denture base acrylic resins. OHDM. 13(4): 1041-1047.

Seifert SM, Schaechter JL, Hershorin ER, Lipshultz SE. 2011 Health effects of energy drinks on children, adolescents, and young adults. Pediatrics. 127:511-28.

Sripetchdanond J, Leevailoj C. 2014 Wear of human enamel opposing monolithic zirconia, glass ceramic, and composite resin: An in vitro study. J Prosthet Dent 112:1141-50.

Takahashi Y, Chai J, Kawaguchi M. 1998 Effect of water sorptionon the resistance to plastic deformation of a denture base material relined with four different denture reline materials. Intern J Prosthods. 11: 49-54.

Topcu FT, Erdemir U, Sahinkesen G, Yildiz E, Uslan I, Acikel C. 2010 Evaluation of microhardness, surface roughness, and 
wear behavior of different types of composite resins polymerized with two different light sources. Biomed Mater Res B Appl Biomater. 92:470-8.

Valinoti AC, Neves BG, Silva EM, Maia LC. 2008 Surface degradation of composite resins by acidic medicines and $\mathrm{pH}-$ cycling. J Appl Oral Sci. 16:257-65.

Voltarelli FR, Santos-Daroz CB, Alves MC, Cavalcanti AN, Marchi GM. 2010 Effect of chemical degradation followed by tooth brushing on the surface roughness of restorative composites. J Appl Oral Sci. 18:585-90.

Yanikoğlu N, Duymuş ZY, Yilmaz B. 2009 Effects of different solutions on the surface hardness of composite resin material. Dent Mater J 28(3): 344-351

Yesilyurt C, Yoldas 0, Altintas SH, Kusgoz A. 2009 Effects of food simulating liquids on the mechanical properties of a silorane-based dental composite. Dent Mater J 28:362-7. 